\title{
Augmentation Mastopexy: Implementing Autologous Breast Tissue for Optimum Results; Case Series Study with a Nine-Month Follow-up
}

\author{
MOHAMED FATHI ABOZEID, M.D., M.R.C.S. England and DINA BADAWI, M.D. \\ The Department of Plastic Surgery, Faculty of Medicine, Cairo University, Egypt
}

\begin{abstract}
Background: Augmentation mastopexy of small and medium sized ptotic breasts presents one of the greatest challenges to plastic surgeons. That because both these procedures have opposing effects on the breast parenchyma and skin. The primary objective of our study is to explore the reliability of the lower pole triangular dermoglandular flap sutured to the pectoral fascia in the improvement of the results regarding both the aesthetic appearance and the long term maintenance.
\end{abstract}

Methods: The study was conducted in Royal Hospital, Cairo, Egypt during the period from June 2013 to December 2015. The study included female patients undergoing augmentation mastopexy; some were implant-based while others were based on the autologous breast tissue, depending on the patient's desire whether to increase the cup size or to retain the same size. All patients were evaluated by detailed history, careful physical examination and photographed pre and postoperative. At the lower pole of the breast, we created a dermoglandular flap which is triangular in shape. We did not dissect it deeply from the pectoralis fascia. The flap was kept at the lower pole in cases of implant-based augmentation. However, in autologous augmentation, it was freed along the margins and mobilized to provide upper and medial fullness. After surgery, all cases were followed up for nine months to assess the outcomes of the procedure.

Results: Sixty subjects were included in the analysis of this study. The age of the patients ranged from 22 to 48 years with a mean age at presentation of 34.1 (6.5) years. All patients requested to improve the projection of the breast together with the lifting of the NAC. Thirty-six patients (60\%) desired to increase the cup size and accordingly underwent implantbased augmentation with mastopexy. Twenty-four patients $(40 \%)$ wanted to retain the same size and therefore underwent auto-augmentation mastopexy. The patients were very satisfied with the outcome of the operation in most of the cases (54 cases), satisfied in 6 cases, and we had no unsatisfied patients.

Statistically, there was a significant $(p<0.001)$ reduction in the cup size during the postoperative follow-up period than in the preoperative cup sizes. Preoperatively, thirty percent of patients were cup size A, 45\% B and 25\% C. Postoperatively, eighty percent of patients were cup size $\mathrm{C}$ and $15 \% \mathrm{~B}$ at all follow-up visits.
The maintenance of improvement of ptosis was measured by the distance between the suprasternal notch (SSN) and 12 O'clock point of the NAC (12'NAC), as well as by the distance between the 6 O'clock point of the NAC (6'NAC) and the IMF. The distance between the SSN to the 12 'NAC varied between 31 and $24 \mathrm{~cm}$ preoperatively (mean $\pm S D: 26.7 \pm 2.1 \mathrm{~cm}$ ), and between 22 and $20 \mathrm{~cm}$ postoperatively at nine months (mean \pm SD: $21.0 \pm 0.8 \mathrm{~cm}),(p$-value $<0.001)$. Besides, the distance between the 6'NAC and the IMF pre-operatively varied between 8 and $12 \mathrm{~cm}$, and at the postoperative followup visits, it ranged from 6.5 to $8 \mathrm{~cm}$, ( $p$-value $<0.001)$.

No complications detected in 44 cases $(73 \%)$, Wound problems (puckering, infection, dehiscence) in $7(12 \%)$ and Asymmetry in $9(15 \%)$. All complications resolved by time.

Conclusion: Finally, we can conclude that the triangular dermoglandular flap proved to (i) provide long-term support for the nipple- areola complex in its new position, (ii) support the breast implant inferiorly, and (iii) increase the mass and the fullness of the upper breast for autologous tissue-based augmentation. The method presented is simple, efficient and competent for both implant-based as well as autologous tissuebased augmentation mastopexy operations.

Key Words: Augmentation mastopexy - Implants - Autologous augmentation - Satisfaction - Complications rate.

\section{INTRODUCTION}

The pathophysiology of the small to medium sized ptotic breasts may be analyzed into redundancy of the skin envelope with the descent of the nipple-areola complex (NAC) together with a parenchymal content that may be disproportionately small or of adequate volume but maldistributed. Hence, the augmentation mastopexy has opposing goals of skin reduction and parenchymal enhancement to restore a youthful look of the breast [1]. Regnault P. (1976) classified the breast ptosis according to the relation of the NAC to the inframammary fold (IMF) and skin brassiere (Table 1) [2]. 
Table (1): The degrees of ptosis as described by Regnault [2].

\begin{tabular}{ll}
\hline The degree of ptosis & \multicolumn{1}{c}{ Description } \\
\hline $\begin{array}{l}\text { First degree } \\
\text { (minor ptosis) }\end{array}$ & $\begin{array}{l}\text { - The nipple lies at the level of } \\
\text { the IMF, above the lower con- } \\
\text { tour of the parenchyma and } \\
\text { skin brassiere. }\end{array}$ \\
$\begin{array}{l}\text { - The nipple lies below the level } \\
\text { of the fold but remains above } \\
\text { (moderate ptosis) } \\
\text { the lower contour of the } \\
\text { breast and skin brassiere. }\end{array}$ \\
$\begin{array}{l}\text { - The nipple lies below the fold } \\
\text { level and at the lower contour } \\
\text { of the breast and skin bras- } \\
\text { (major ptosis) } \\
\text { siere. }\end{array}$ \\
$\begin{array}{l}\text { - The nipple lies above the sub- } \\
\text { mammary fold level but the } \\
\text { major portion of breast paren- } \\
\text { chyma lies below the IMF }\end{array}$ \\
\hline
\end{tabular}

An anatomic-based approach, which relies on reshaping and tightening the breast parenchyma to support the NAC in its new position, must be adopted to minimize the incidence of secondary ptosis. The primary target of skin resection here is to remove the excess skin and not to support the breast lift which is more preferred than relying on the "skin brassiere" because the latter may lead to wound dehiscence, scar widening, and failure to provide permanent results [3].

Moreover, implants have its disadvantages. Implant displacement is the second most common source of patient psychological distress after capsular contracture. Usually, this involves the inferior migration of the implant due to the disruption of the IMF [4].

Besides, most techniques developed to correct the ptotic breasts fail to address the problems of the loss of the upper pole and medial fullness [5]. That is often disappointing for the patients looking for the medial cleavage. However, a new trend is adopted by some surgeons by providing lipofilling after the breast augmentation [6].

Many authors recognized the efficiency of an inferior pedicle glandular flap as a reliable flap with the robust blood supply that is obtained from the perforators of the fourth, fifth, sixth, and seventh intercostal arteries from the internal thoracic artery [7].

Ribeiro (1989) used inferior dermo-lipoglandular pedicle flap to increase the upper pole fullness and projection resulting in an inverted Tshaped scar [8]. Others placed it beneath a superior pedicle to correct ptosis and to increase the projection and apparent volume of the breast following breast implant removal [9].
Thus, the rationale intended for the current study was to explore the efficiency and safety of the lower pole triangular dermoglandular flap sutured to the pectoral fascia as a reliable procedure for augmentation mastopexy with or without implants.

\section{PATIENTS AND METHODS}

This case-series study was conducted during the period from June 2013 to December 2015 with nine-month follow-up period in Royal Hospital, Cairo, Egypt. The goal of this study was clearly explained in the Arabic language to all subjects before their enrollment to the study, and an informed consent form was signed by and obtained from all of those enrolled.

We recruited 60 female patients, between 18 to 50 years, who were willing to undergo augmentation mastopexy.

Exclusion criteria included: American Society of Anesthesia score 3 or 4 (high risk for anesthesia), patients with organ failure, diabetes mellitus, and collagen vascular diseases, and patients with bleeding tendencies.

\section{Preoperative and postoperative patient assessment:}

All patients were evaluated by detailed history, careful physical examination and photographed pre and postoperative using Nikon d3200 DSLR Camera, $18-55 \mathrm{~mm}$ lens. Photography views were standard anteroposterior, midlateral, and lateral views. Smoking was stopped at least three weeks before the procedure.

History included: age of the patient, history of cardiac problems, liver disease, renal disease or a recent drug intake. Adequate physical examination with stress on the following points was done: The general examination includes signs of renal failure or liver disease. A detailed examination was done to assess for the current breast size, the degree of ptosis, and the status of the breast parenchyma.

We explained to the patient about the incision, the scars, the idea of the operation, discussion with her to know their expectations.

Patients were assessed preoperatively, immediately post-operation, and at three, six, and nine months postoperative follow-up. Photos were taken in each visit.

\section{Laboratory investigations:}

Blood samples were taken from patients as routine preoperative preparation for complete blood picture, coagulation profile, liver \& kidney functions and random blood sugar. 


\section{Preoperative markings:}

We marked the suprasternal notch, the midline, and the inframammary folds while the patient in the standing position. Then, we measured the distances between the suprasternal notch and the NAC and between the NAC and the IMF. After that, we marked the breast meridians with the new nipple at the anterior reflection of the IMF along with the meridian, and with a diameter of the new areola of $38-40 \mathrm{~mm}$ according to the breast width. Finally, we drew the marking of Lejour technique of vertical scar mastopexy while the patient still in the standing position (Fig. 1).

\section{Operative technique:}

For all cases:

Operations in all cases were done under general anesthesia with the patient in the supine position. First, deepithelialization of the mastopexy flap was made (Fig. 2). Then, by the aid of electrocautery, the dissection was performed through the breast parenchyma down to the pectoralis major fascia, along the margins of the deepithelialized skin, creating the upper pedicle carrying the NAC, and leaving an intact undissected triangular flap at the inferior pole with an apex and a base $2 \mathrm{~cm}$ and $4 \mathrm{~cm}$ from the IMF, respectively (Fig. 3).

For the cases undergoing implant based augmentation:

Under direct visualization, with an electrocautery connected to a fine Colorado needle, a pocket was precisely dissected between the pectoralis muscle fascia and the gland, according to the diameter of the proposed implant (Fig. 4). Then, the implant was placed in its pocket. We routinely used cohesive gel filled, textured, and round implants. The choice of the base was according to the patient's bony chest dimensions, and the volume according to where the projection was determined according to the patient's desire and under the surgeon's pre- and intraoperative judgment (Fig. $5)$. After that, the superior pedicle carrying the NAC was repositioned over the implant with its lower margin sutured to the upper margin of the undissected lower pole triangular dermoglandular flap (Fig. 6). Here, the lower pole triangular dermoglandular flap was left intact in place to provide glandular support to the NAC in its new position, to support the implant preventing its inferior migration, to preserve the inframammary fold, and to prevent its violation during dissection or by the migrating implant.

For cases undergoing augmentation mastopexy:

The lower pole triangular dermoglandular flap was freed from the medial and lateral pillars of the breast, and left intact deeply, undissected from the pectoral fascia (Fig. 7). Then, the two pillars were approximated by stay sutures. After that, any contour deformity in the form of lack of fullness or lack of cleavage was assessed (Fig. 8). Then, the stay sutures were removed, and the triangular flap was mobilized to fill any emptiness encountered, and sutured to the pectoral fascia with 2-3 (polydioxanone) PDS sutures (Fig. 9). Finally, the medial and lateral glandular pillars were sutured burying underneath the triangular flap in its new position.

In all cases (whether autologous-tissue based or implant-based):

After ensuring a full rounded lifted breast and the NAC placed centrally over the highest bulge and well supported by breast parenchyma, it was secured to its new position, and the uppermost borders of the medial and lateral breast pillars were approximated to define the new lower margin of the NAC (Fig. 10). Then, the circum-vertical incisions were closed in layers (Fig. 11).

\section{Outcome measures:}

The primary outcome measure was to assess the success of the lower pole triangular dermoglandular flap-sutured to the pectoral fascia-as a reliable procedure for augmentation mastopexy with or without implants. The assessment was to be done by the objective evaluation of aesthetic results using the breast cup size pre and postoperative at 3,6 and nine month and the distance between the suprasternal notch (SSN) and 12 O'clock point of the NAC (12'NAC), in $\mathrm{cm}$, pre and postoperative at nine months. Moreover, the distance between the nipple areola complex to inframammary fold (6'NAC-IMF) in $\mathrm{cm}$ pre and postoperative at 3, 6 and 9 month was to be added for further assessment.

The secondary outcome measures were to quantify the short-term and long-term complications, as well as, to assess patients' satisfaction with results. Patients' satisfaction was to be measured by using a satisfaction scale, where, three is very satisfied (the results matched all the patient's desires), two is satisfied (not all the expectations were met, but still satisfied and do not request reoperation or secondary procedure), and one is unsatisfied [requiring re-operation or secondary procedure (e.g.: lipofilling)].

\section{Statistical analysis:}

All statistical tests were done using a significance level of $95 \%$. A value of $p<0.05$ was considered statistically significant. SPSS software (Sta- 
tistical Package for the Social Sciences, version 20.0, SSPS Inc, Chicago, IL, USA) was used for the statistical analyses. Data were presented as (mean $\pm \mathrm{SD}$ ) or median (range) for continuous

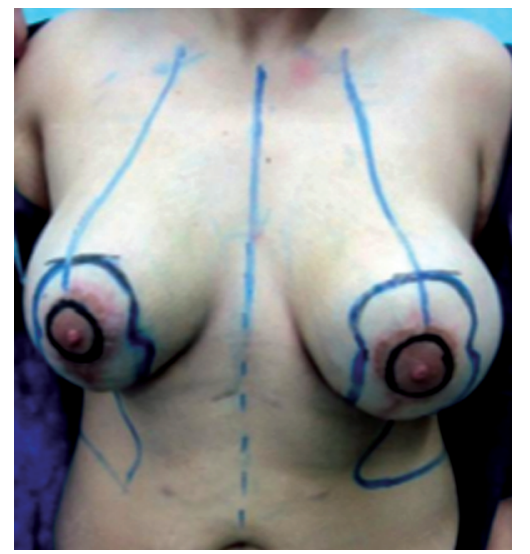

Fig. (1): The pre-operative markings with the patient standing.
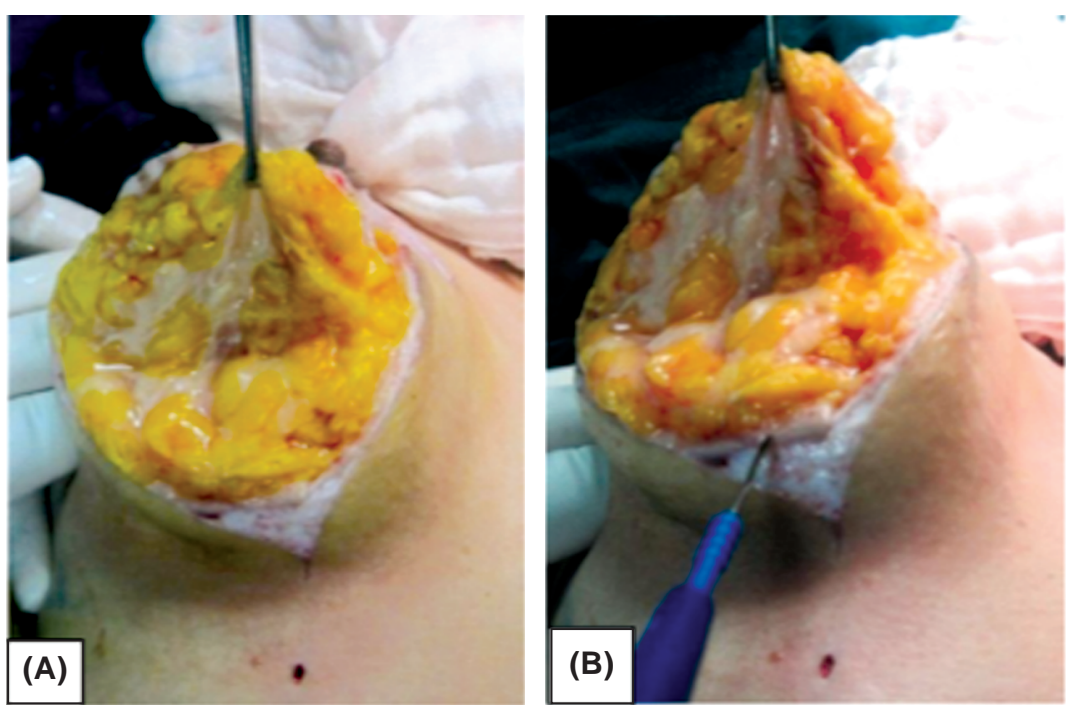

Fig. (3): (A) The superior pedicle carrying the NAC is separated from the lower traiangular flap. (B) The colorado needle pointing to dermmoglandular flap.

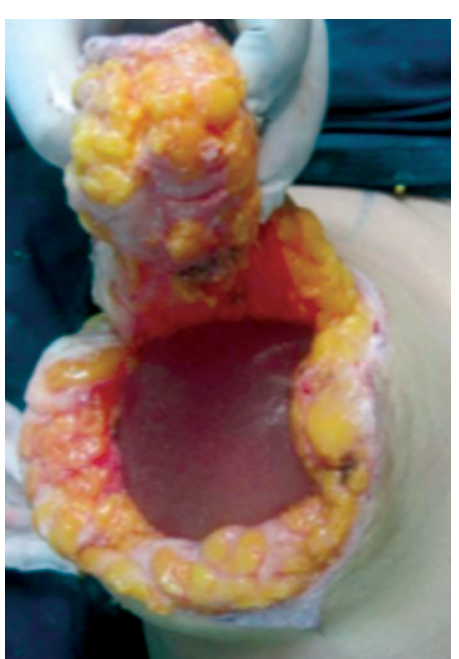

Fig. (5): The implant placed in the pokcket. variables and as a frequency and percent for categorical variables. Comparisons were made using the paired $t$-test for continuous variables and Chisquare test for categorical variables.

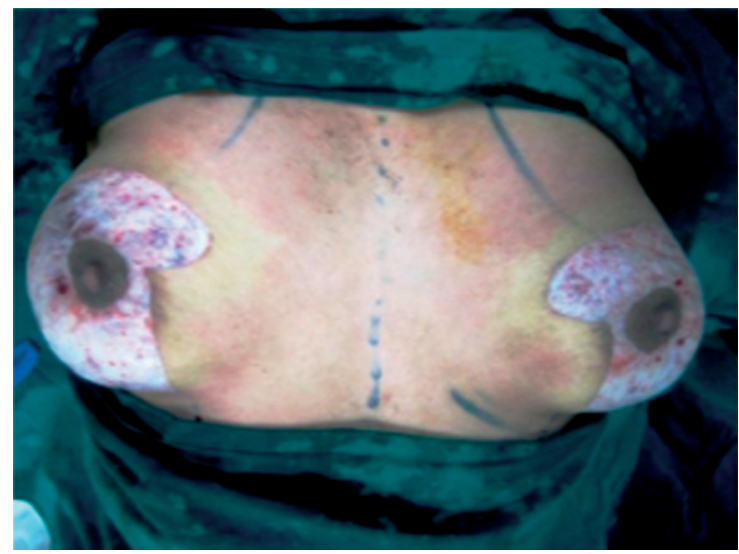

Fig. (2): De-epithelialization of the mastopexy flaps.

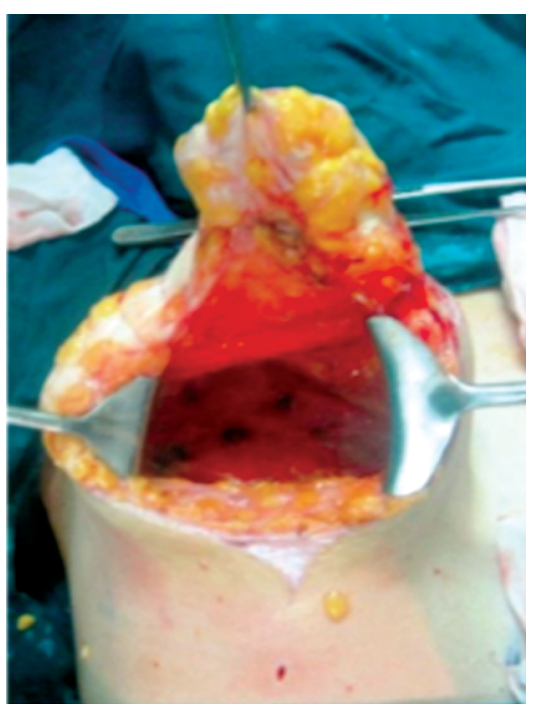

Fig. (4): The implant pokcket dissected.
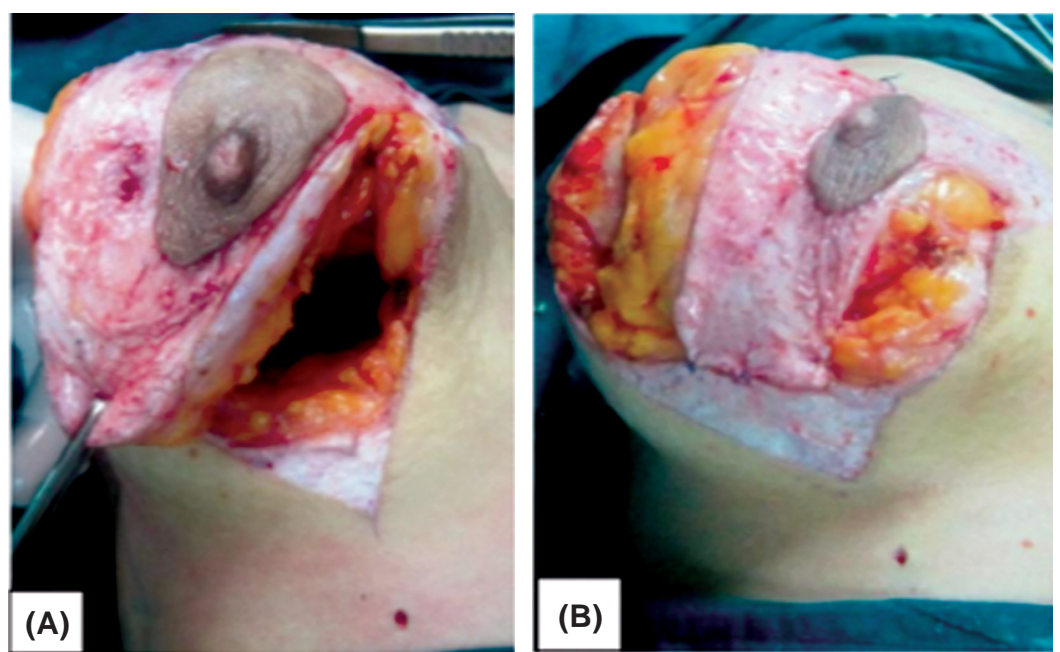

Fig. (6): (A) The NAC carrying pedicle is redrapeed over the implant and (B) Sutured to the upper margin of the undissecteed lower pole triangular dermoglandular flap. 


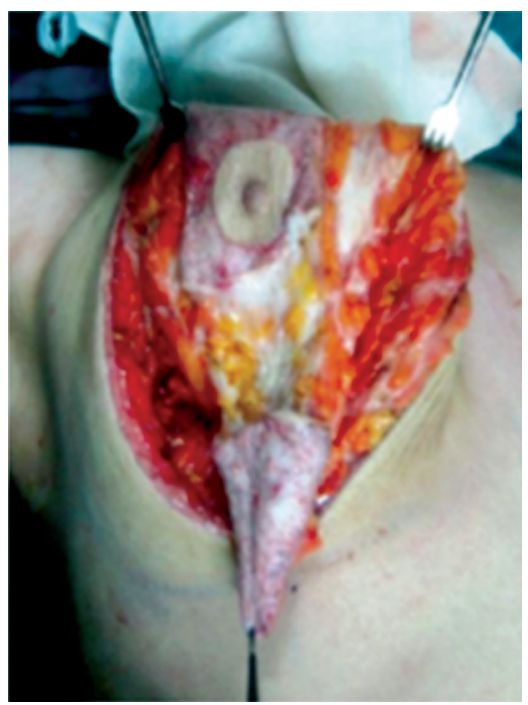

Fig. (7): The triangular dermoglandular flap freed along its lateral margins.

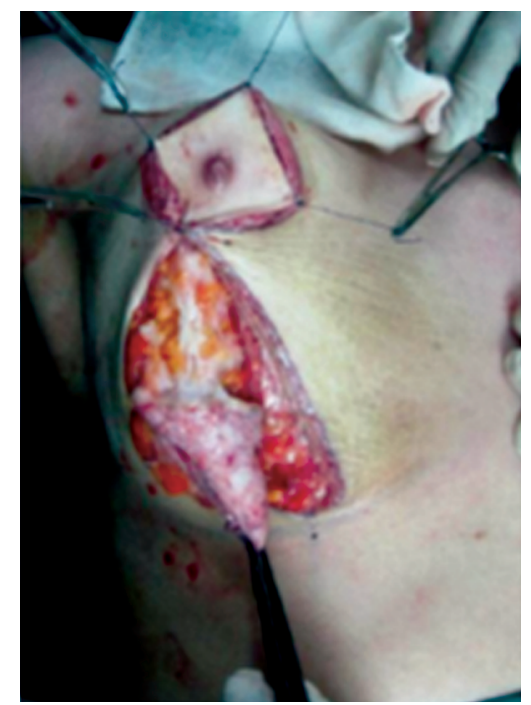

Fig. (8): At assessment before difinitive closure, a medial emptiness is noted.

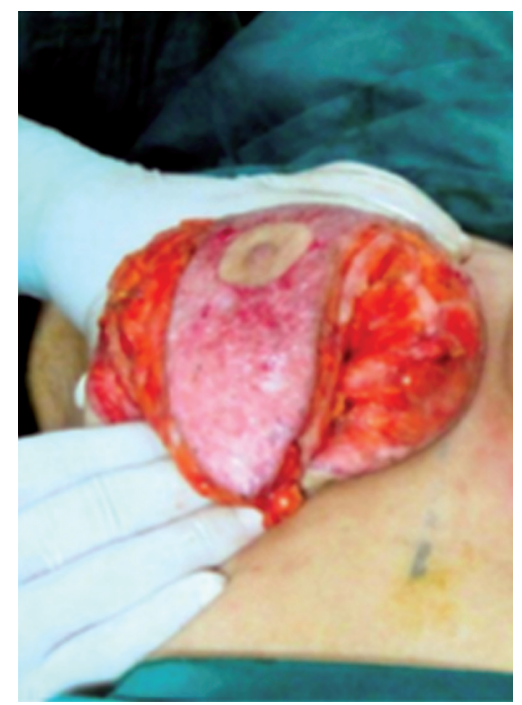

Fig. (9): The lower pole dermoglandular flap is mobilized to provide medial fullness, sutured to the pectoral fascia, then buried by the closure of the medial and lateral pillars.

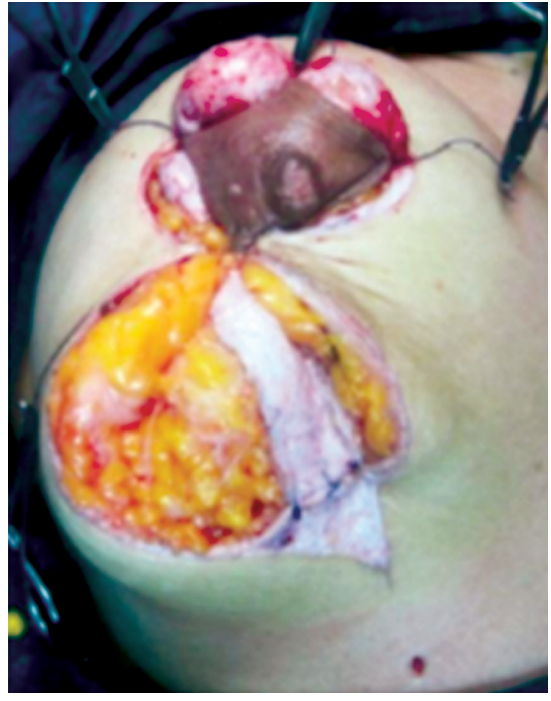

Fig. (10): Suturing the NAC in its new position.

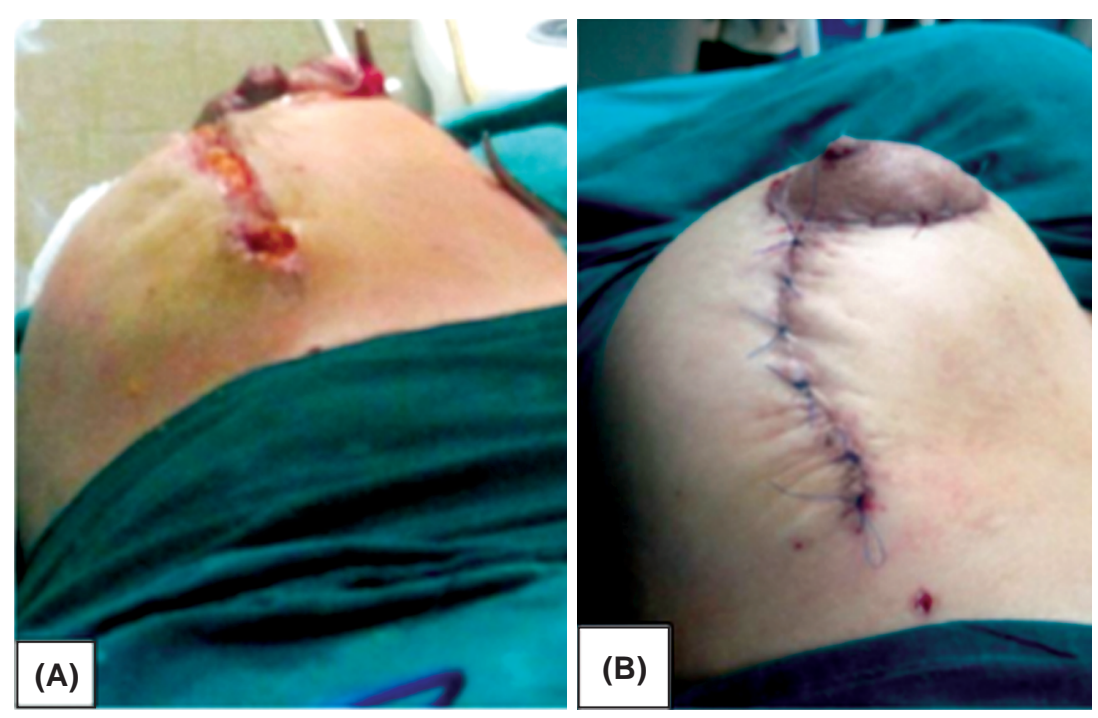

Fig. (11): (A,B) Closure of the circum-vertical incision in layers.

\section{RESULTS}

Baseline characteristics and operative details:

All sixty patients have had small or mediumsize breasts with different degrees of ptosis (Table 2 ). The age of the cases ranged between 22 and 48 years (mean age: $34.1 \pm 6.5$ ).

All patients requested to improve the projection of the breast together with the lifting of the NAC.
Thirty-six patients $(60 \%)$ wanted to increase the cup size and accordingly underwent implant-based augmentation with mastopexy (implants used were cohesive gel filled, textured and round with volume varying between $225 \mathrm{cc}$ and $465 \mathrm{cc}$ ). Twenty-four patients (40\%) desired to retain the same size and therefore underwent auto-augmentation mastopexy. 
Table (2): Degree of ptosis: Preoperative.

\begin{tabular}{lcc}
\hline The degree of ptosis & Number & $\%$ \\
\hline First degree (minor ptosis) & 18 & 30 \\
Second degree (moderate ptosis) & 30 & 50 \\
Third degree (major ptosis) & 12 & 20 \\
\hline
\end{tabular}

Operations were done in the period between June 2013 and December 2015 with a 9-month follow-up period, to assess the long-term results of the technique.

The postoperative assessment: Patients' satisfaction:

Patients were asked about overall satisfaction, particularly, satisfaction with shape, scar length, and nipple sensation after the operation. The patients were very satisfied in most of the cases (54 cases), satisfied in 6 cases, and we had no unsatisfied patients. That was principally attributed to patient's counseling, examination, and education. All cases with auto-augmentation were very satisfied 24 cases ( $40 \%$ of all cases). However, 30 cases of implant group (50\% of all cases) were very satisfied, and 6 cases (10\% of all cases) were satisfied, as shown in Fig. (12).

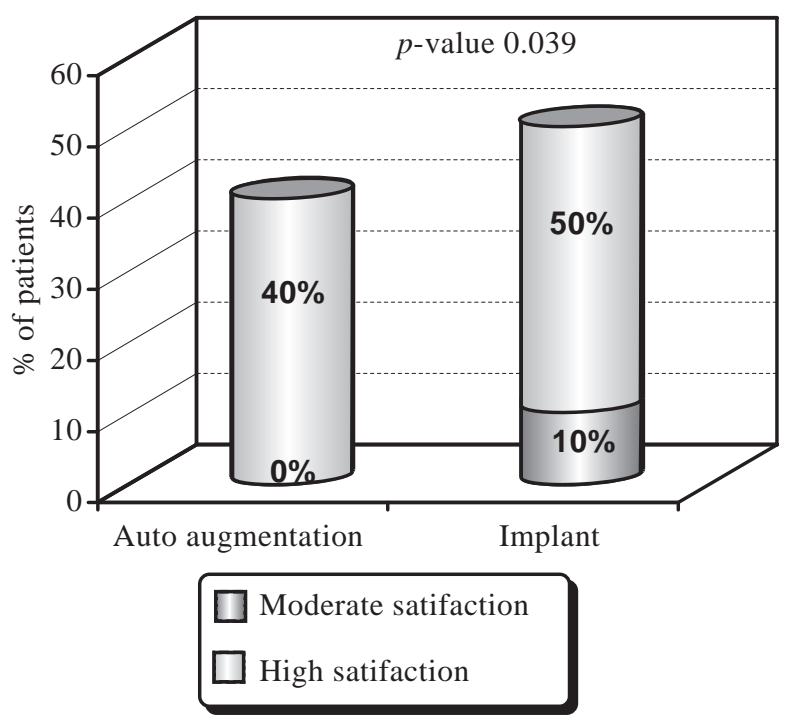

Fig. (12): Patients postoperative overall satisfaction.

\section{The postoperative assessment: Cup size.}

Statistically, there was a significant $(p<0.001)$ reduction in the cup size during the postoperative follow-up period than in the preoperative cup sizes. Preoperatively, thirty percent of patients were cup size A, $45 \%$ B and $25 \%$ C. Postoperatively, eighty percent of patients were cup size $\mathrm{C}$ and $15 \% \mathrm{~B}$ at all follow-up visits, (Fig. 13).

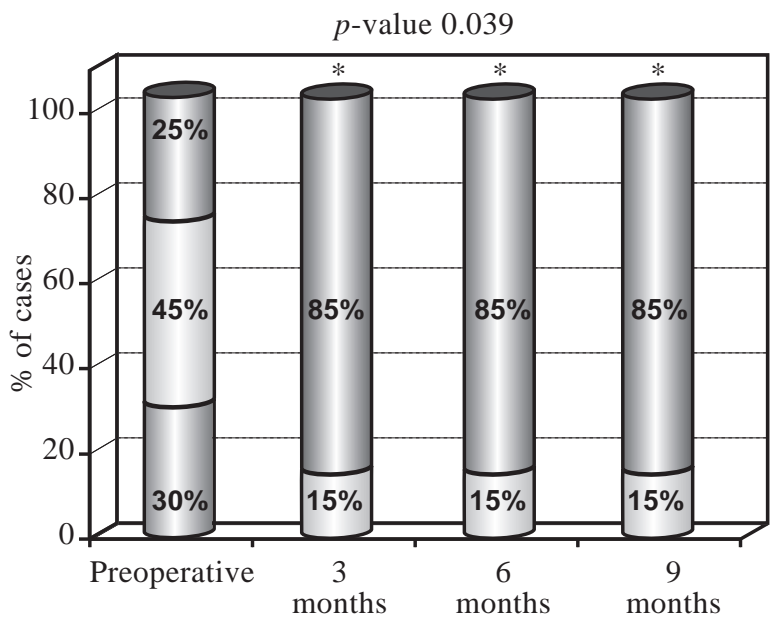

$\square$ Cup size A $\square$ Cup size B $\square$ Cup size C

Fig. (13): Cup size; pre and postoperative.

The postoperative assessment of ptosis:

The maintenance of improvement of ptosis was measured by the distance between the suprasternal notch (SSN) and 12 O'clock point of the NAC (12'NAC), as well as by the distance between the 6 O'clock point of the NAC (6'NAC) and the IMF. The distance between the SSN to the 12'NAC varied between 31 and $24 \mathrm{~cm}$ preoperatively (mean \pm SD: $26.7 \pm 2.1 \mathrm{~cm}$ ), and between 22 and $20 \mathrm{~cm}$ postoperatively at nine months (mean \pm SD: $21.0 \pm$ $0.8 \mathrm{~cm}),(p$-value $<0.001)$ (Table 3$)$.

Table (3): SSN- to 12 'NAC distance in $\mathrm{cm}$.

\begin{tabular}{lcc}
\hline & Preoperative & $\begin{array}{c}9 \text { months } \\
\text { Postoperative }\end{array}$ \\
\hline Mean & 26.7 & 21.0 \\
Standard deviation (SD) & 2.1 & 0.8 \\
Median & 26 & 21 \\
Minimum & 24 & 20 \\
Maximum & 31 & 22 \\
\hline$p$-value & & $<0.001$ \\
\hline
\end{tabular}

We documented that changes in the SSN12 'NAC and 6'NAC-IMF measures between immediate and nine months postoperative were $<0.6 \mathrm{~cm}$.

The distance between the 6'NAC and the IMF pre-operatively varied between 8 and $12 \mathrm{~cm}$, and at the postoperative follow-up visits, it ranged between 6.5 and $8 \mathrm{~cm}$, ( $p$-value <0.001) (Table 4).

\section{Postoperative complications:}

No complications detected in 44 cases $(73 \%)$, Wound problems (puckering, infection, dehiscence) 
in $7(12 \%)$ and Asymmetry in $9(15 \%)$, as shown in Table (5). The seven cases had vertical partial wound dehiscence that resolved with medical treatment and local care. Nine cases had immediate

Table (4): NAC to IMF distance in $\mathrm{cm}$.

\begin{tabular}{lcccc}
\hline & & \multicolumn{3}{c}{ Postoperative } \\
\cline { 3 - 5 } & Preoperative & 3 & 6 & 9 \\
& & 7.1 & 7.1 & 7.2 \\
& 9.4 & 0.4 & 0.4 & 0.4 \\
\hline Mean & 1.2 & & & \\
Standard & & 7.0 & 7.0 & 7.1 \\
$\quad \begin{array}{l}\text { deviation (SD) } \\
\text { Median }\end{array}$ & 9.3 & 6.5 & 6.5 & 6.5 \\
Minimum & 8.0 & 8.0 & 8.0 & 8.0 \\
Maximum & 12.0 & $<0.001$ & $<0.001$ & $<0.001$ \\
\hline$p$-value & & & & \\
\hline
\end{tabular}

postoperative asymmetry that settled within three months spontaneously with the resolution of inflammation, edema, puckering and with the complete healing of the wounds.

Table (5): Postoperative complications.

\begin{tabular}{lcc}
\hline & $\begin{array}{c}\text { Number of } \\
\text { patients }\end{array}$ & $\%$ \\
\hline No complication & 44 & 73 \\
Wound problems & 7 & 12 \\
$\quad$ puckering, infection, dehiscence) & & 1 \\
Asymmetry & 9 & 5 \\
NAC necrosis & 0 & 0 \\
Seroma & 0 & 0 \\
Hematoma & 0 & 0 \\
\hline
\end{tabular}

Cases:

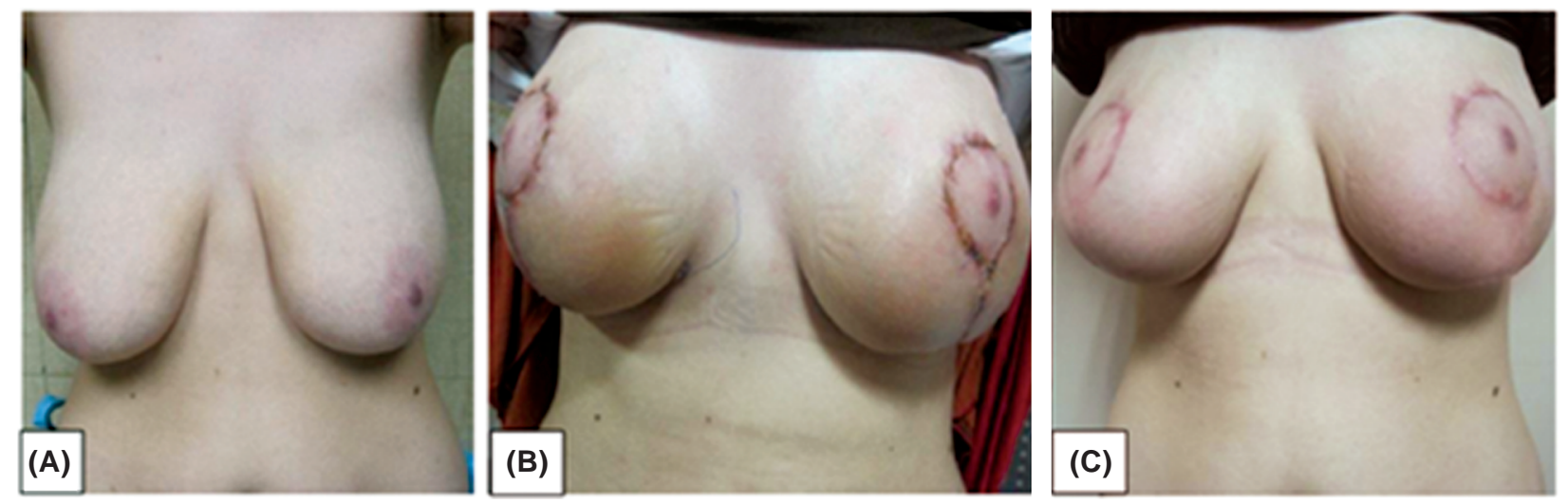

Fig. (14): A case of autoaugmentation mastopexy. (A) Pre-operative, (B) 1 week post-operative and (C) 9 months post-operative.
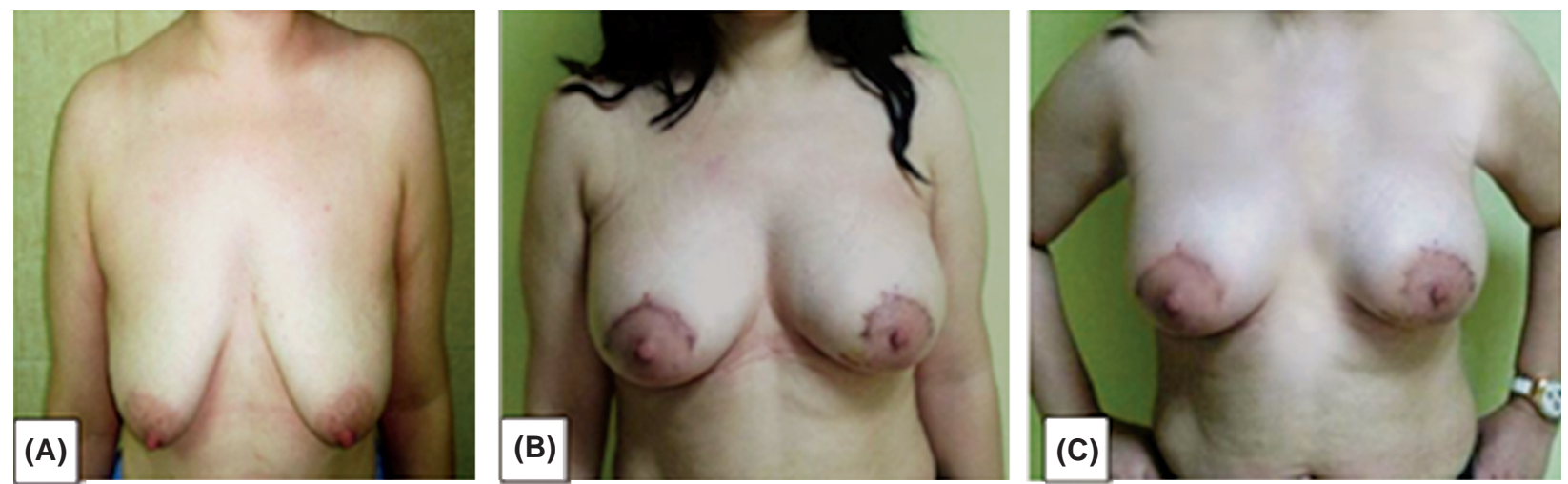

Fig. (15): A case of implant augmentation mastopexy (265 cc). (A) Pre-operative, (B) 1 week post-operative and (C) 9 months post-operative.

\section{DISCUSSION}

Different surgical techniques are introduced to correct Regnault grade II and III ptosis. With the addition of the task of increasing the apparent or the actual breast volume, innovations are continuously evolving. However, these techniques should not only be evaluated concerning their good shortterm outcomes but also their long-term maintenance of the postoperative outcome, which may be sometimes disappointing [10].

The results of our study showed that this deepithelialized dermoglandular triangular lower pole 
flap with its blood supply preserved through keeping intact relation with the pectoral fascia is a reliable procedure for augmentation mastopexy with or without implants. The procedure was successful in all subjects with a high satisfaction of the outcomes as a subjective measure of satisfaction added to the doctors' assessment of the maintenance of improvement of ptosis by the objective measurements of the distance between SSN and 12'NAC in $\mathrm{cm}$ and the distance between the 6'NAC and the IMF. The achieved cup sizes of the patients were maintained throughout the entire follow-up period. All postoperative complications (wound problems or asymmetry) were resolved completely during the follow-up period.

In reviewing the medical literature for various techniques of augmentation mastopexy, we found that some surgeons reached conclusions by assessing the patients for six months postoperatively [11], others for 9.5 months follow-up [12], and others reached a mean follow-up of 12 months [9]. Throughout our study, we found $100 \%$ compliance within the first nine months follow-up, which enabled us to get trustworthy and reliable data.

For the assessment of the long-term results of mammoplasty, a comparative analysis of different mammoplasty techniques concluded that the measurement of the vertical distance between the most caudal portion of the NAC and the inframammary crease scar is a straightforward and reliable method [7]. Along with this approach, we also added the measurement of the distance between the suprasternal notch to the upper margin of the NAC to assess the efficiency and longevity of the results of our technique. We found these measures to be entirely objective, easily obtained, and helpful when comparative data is needed.

For the goal to improve breast projection and upper pole fullness, Graf and Biggs (2002) suggested a technique using the inferior thoracic flap [13]. However, this method entailed disruption of normal breast architecture by burying breast parenchyma under a bulk of pectoralis muscle. In some cases, this may cause noticeable "pulling" of breast parenchyma as a result of muscle contracture [10]. We agree with Silfen et al., (2009) [10] that using the pectoralis muscle fascia exclusively achieves more durable autologous breast parenchymal suspension. Moreover, it avoids adding extra tension on the wounds by not relying on the skin brassiere to hold the breast parenchyma in its lifted position. In our technique, we made more use of the pectoralis fascia to suspend the lower pole pedicled flap medially or superomedi- ally, and also to support the implant inferiorly by keeping the lower pole flap attached to the pectoralis fascia. Both techniques helped to add more longevity to the mastopexy augmentation results by holding the parenchymal fullness placed centrally, deep to the NAC without adding tension on the skin flaps.

Finally, we think that this technique with its maintained success in those types of patients is a reliable option than can be considered as it is a simple, rather efficient and satisfactory method to improve the results of the augmentation-mastopexy operations, whether implant-based or autologous tissue-based.

\section{Conclusion:}

We can conclude that the deepithelialized dermoglandular triangular lower pole flap is a reliable method to optimize the results of the augmentation mastopexy with or without implant. The flap proved to provide long-term support for the NAC in its new location, maintain the implant inferiorly. Besides, the operation adds volume and upper breast fullness for auto-augmentation.

\section{Declaration of interest:}

All authors declare that no conflict of interest could be perceived as prejudicing the impartiality of the research reported.

\section{Funding:}

This research did not receive any specific grant from any funding agency in the public, commercial or not-for-profit sector.

\section{REFERENCES}

1- Davison Steven P. and Clemens Mark W.: Breast Augmentation with Periareolar Mastopexy. In Melvin A. Shiffman. Breast Augmentation. Berlin Heidelberg: Springer Science \& Business Media, 2009.

2- Regnault P.: Breast ptosis: definition and treatment. Clin. Plast. Surg., 34 (2): 193-203, 1976.

3- De La Torre, Jorge, Long, James and Vasconez Luis: History of mastopexy. In Melvin A. Shiffman. Mastopexy and Breast Reduction: Principles and Practice. Berlin Heidelberg: Springer Science \& Business Media, 2009.

4- Erian, Anthony and Dass Amal: Complications of Breast Augmentation. In Melvin Shiffman. Breast Augmentation: Principles and Practice. Berlin Heidelberg: Springer Science \& Business Media, 2009.

5- Hamdi M. and Tuncer S.: Breast surgery in patients after massive weight loss. In Atiyeh B S. Body contouring following bariatric surgery and massive weight loss. Benthams Books, pp. 102-111 (10).

6- Harvey J., Down S., Bright-Thomas R., Winstanley J. and Bishop H.: Breast Disease Management: A Multidiscipli- 
nary Manual. Oxford: Oxford University Press, pp. 187$192,2014$.

7- Alexandre Andrade Souza L.F., de Azevedo Ferreira Á, et al.: Comparative analysis of mammaplasty techniques based on the long-term effect on the nipple-areolarcomplex to inframammary crease distance. Rev. Bras. Cir. Plást., 26 (4): 664-669, 2011.

8- L. Ribeiro: Cirurgia plástica da mama. Rio de Janeiro: Medsi, p.7129-83, 1989.

9- Hönig J.F., Frey H.P., Hasse F.M. and Hasselberg J.: Inferior Pedicle Autoaugmentation Mastopexy After Breast Implant Removal. Aesthetic Plastic Surgery, 34 (4): 447454, 2010.
10- Ritz M., Silfen R. and Southwick G.: Fascial suspension mastopexy. Plastic and Reconstructive Surgery, 117 (1): 86-94, 2006.

11- Kirwan L.: Augmentation of the ptotic breast: Simultaneous peri-areolar mastopexy/breast augmentation. Aesthet. Surg. J., 19 (1): 34-39, 1999.

12- Franco J., Kelly E. and Kelly M.: Periareolar augmentation mastopexy with interlocking gore-tex suture, retrospective review of 50 consecutive patients. Arch. Plast. Surg., 416: 728-733, 2014.

13- Graf R. and Biggs T.M.: In search of better shape in mastopexy and reduction mammoplasty. Plast. Reconstr. Surg., 110: 309-17, 2014. 